\begin{tabular}{l|l|l} 
This produces a tulip-shaped flame, and it has a I made a further examination into the question; and \\
specially constructed glass arrangement on the outside & the results arrived at will be those here quoted. The
\end{tabular} for regulating the combustion. Comparing the abovementioned burners with each other, we arrive at the following results: The "Lillois" burner consumes 70
liters of gas per carcel; the Siemens ordinary, 70 Witers; the siemens-Beit Taking this into and considering that a carcel corresponds with 105 liters of gas consumed in the Bengel form of burner, we see that the economy in gas might, by employing these
burners, reach from 33 to 71 per cent. If this is compared with the batswing burner, which produces the light of 1 carcel with a consumption of 120 liters of gas, of lamp, from 41 to 85 per cent.

\section{SYNCHRONIZING CLOCKS.}

AT the reeent meeting of the Institution of Mechan ical Engineers, Dublin, Mr. Davey, or Leeds, spoke of synchronizing mechanisms. He had occupied some of
his spare time in attempting to synchronize clocks from a standard clock. The problem is sinuilar to the

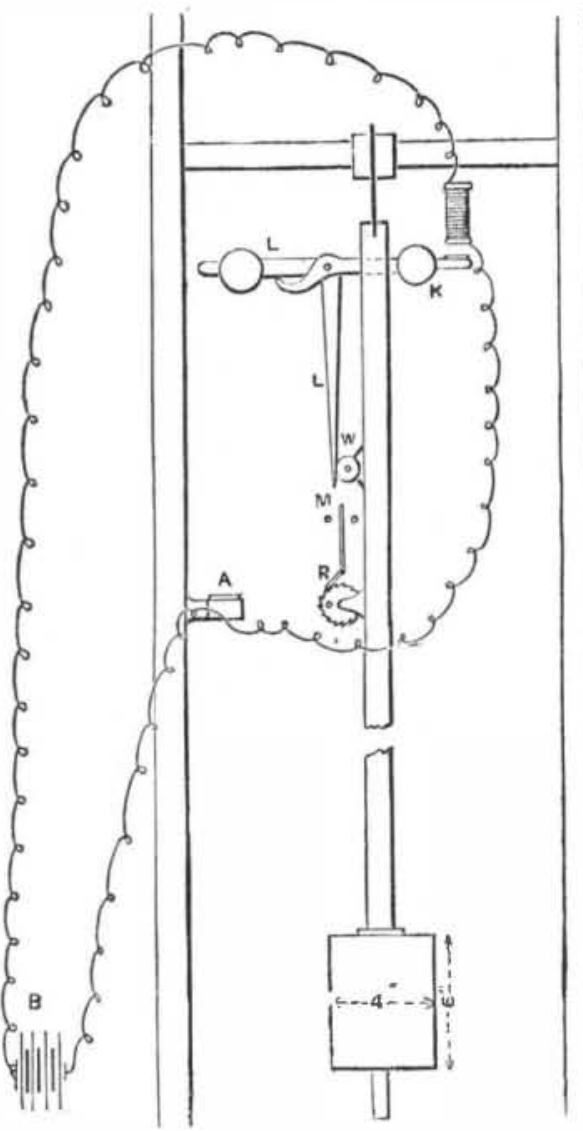

DAVEY'S PENDULUM FOR SYNCHRONIZING CLOCKS.

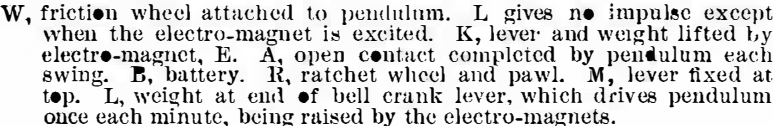

present one, except that it is rough-and-ready, compendulum, to drive a seconds pendulum by electricity. Electrical clocks are notoriously bad timekeepers; on account of variation in the strength of the electrical
current, the battery falls off. He had constructed an ing an impulse once a seconcs pendulum, and recordhad a little ratchet wheel, $\mathrm{R}$ having thirty teeth. The pawl was connected with a lever, M, fixed at the top. wheel. On the side of the clock case was a contact
wintates with the maker, which closed the circuit by the pin on the
ratchet wheel, $R$, once every minute. The weight was ratchet wheel, $R$, once every minute. The weight was
lifted by the electric current, and by its fall gave an impulse to the pendulum. The pendulum was a free
swinging pendulum for 59 sec., and the increase of the are could searcely be detected.

COAL TAR AS FUEL FOR STEAM BOILERS. By John M'Crak, of Dundee. ABDUT three years ago, when the sudden and serious
fall took place in the value of the secondary products
produced in gas works, many gas maragers-ever deproduced in gas works, many gas managers-ever dewere forced to look around for some better market in which to dispose of the products which had so seriously
fallen in value. This was no easy task; and even now it forms very uphill work indeed. A comparatively new market has been created for the disposal of boiled tar at several of the German ports. But the expense
and difficulty of loading ships with tar in casks take very much from the saving derived from the new man-
ner of disposal. It occurred to me, therefore, that we
must look nearer home for a remedy.

In all gas works of any magnitude, a considerable quantity of fuel must be employed for the purpose of supplying the works with steam for the exhauster engines, chemical apparatus, thawing purposes, etc. the least affect or alter my tigures. I have no doubt if an y manager discovers that he is working more economi-
cally by selling the coke and using a cheap small or cally by selling the coke and using a cheap small or
other coal he will adopt the cheapest process. In
Dundee, where Dundee, where we get a good price for coke, I found, to buy small coal costing from $5 \mathrm{~s}$. to $5 \mathrm{~s}$. $6 \mathrm{~d}$. per ton deto buy small coal costing from 5s. to 5s. 6d. per ton de- ing with the large quantity of tar we have for sale
livered in the works, and dispose of the coke. The $\mathrm{d}$ uring the winter. A large portion of the value of our
questlon of fuel then lay between coal and tar; and I I tar must, therefore, go to the railway company, to have experimented some what extensively to ascerta $n$ cover the cost of transit between the two points, and the purpose of this paper, and within the last few fays, so the tar distiller can allow us but a small figure for far distant from the coal fields, the coal is exception-
ally high in price. I quite believe that in many of the west country towns the coal for which we are paying we are receiving $4 \mathrm{~s}$. per ton, they would get not much wnder the double of this. Therefore, you see, in a under the double of this. Therefore, you see, in pe most inisleading. Still, I doubt not there are places as badly situated as Dundee; and it is to such places many towns distant from collieries, the tar might be many towns distant from collieries, the tar might be
sold to manufacturers for use in their steam boilers and such an arrangement would, I think, prove advan I think that as much has been said in regard to my subject as is necessary; but permit me to add that 1 believe there is a future for liquid fuels. I do not say
tar, but more concentrated fuels, such as crude naphthas, paraffins, and pitch oil. When you see one of our large steamers taking coal into her bunker, it must hower here. Every ton of there was great waste of power here. Every ton of coal lait in must require a coal so laid in reduces the cargo-carrying power to this
extent. A few gallons of oil will give you the steamproducing power of a ton of coal; and this is a fact which the owners of non-paying steamships should
note. Take our locomotives also. Everything I have said in regard to steamships applies to them; and the comfort to the stokers and the general reduction in be argued that if there were such a large demand created for oils for furnaces, the old fashioned law of
supply and demand might come into play, and so force up the price of the article for which the increased deters is rather remote, when we bear in mind the oreat oil wells only now from which can be run in bulk direct from the wells into ships, and brought to thi
rates.-Journal of Gas Lighting.

WATCH CLEANING AND REPAIRING. By "OLD FOGY."

BEFORE proceeding with what I consider the best methods in this department of the watch and jewelry business, I will say that I do not, by any means, con-
sider that my way is the best, for although I have sider that my way is the best, for although I have
been in the business quite a while, yet I find that I expect to do so, so long as I continue in the business. Be very particular in selecting your tools ; about three
widths of screwdrivers, and keep them in the best of
order, square across the point of blade, and never use arder, square across the point of blade, and never use and in using be careful not to let it slip, and thus ma the plates or bridges of a watch. I also recommen shapes or styles, so as to save time in picking up the one you want (and just here I will say that every dethe operator); then have about the same number of tweezers (3), one of good, solid, heavy points, say 1 inch wide at the points, for taking down a watch, and
handline the heavier parts, and then one a little pressure steam passes, also into the furnace. The handline the heavier parts, and then one a little finer,
meaning of this steam moving along with the tar is to and one very fine to work in about the train, hair force a draught, as well as to raise the temperature of spring, etc., and always keep these tweezers in perfect the tar, and so partially convert the tar into vapor; ; order at the points, so that whatever you handle, you thereby making the combustion more complete. The flow of the tar is regulated by the very delicate sluices
attached to the injectors. These valves consist of elongated cones and plags, and are constructed not only for removing any obstruction or incrustation which may accumulate in the nozzle. In order to keep the tar in
liquid state (which in the winter time is not an easy matter), a small steam pipe is passed through the center
of the tar pipe; but, of course, no steam is discharged mong the tar, as the presenee of water in the injector
prevents its correct working. The steam pipe is simply assed through the tar pipe, and a steam trap attached o its end. In changing from the coal or coke fuel to arely is a shovelful of any kind of solid material re-
uired. The furnace bars have only to be kept covered quired. 'The furnace bars have only to be kept covered
prevent the waste of tar and the too rapid ingress of air ; and when the furnaces are in full work, and being
well and carefully attended to, the tar will be found to have been nearly al consumed before reaching the
solid material covering the bars. The action is very much the same as in the paraffin oil lamp. The wick
is the of combustion, where it is developed into light; but the wick remains little injured, although in close proxIt will be easily understood that a little experience is
It necessary to enable the attendant to fully understand o obtained, and which in no case must be exceeded. The moment one atom of tar is sent into "the furnace
beyond that which can be thoroughly consumed, you

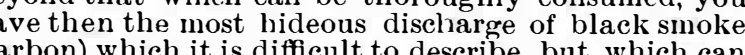
be easily understood, and, I believe, can be seen within u few miles of where we now sit. I should mention the connections are of such a nature that the doors can be opened without disturbing any of the permanent
fittings. And now I have told you that the results detailed in this short paper were those obtained in the Dundee
gas works. This is so; but were I to leave the matter here, it might be inferred that I considered similar reI would not mislead you; and therefore must detain you for a few momentslonger in order to show you how very peculiarly situated in this others. Dundee is istance from any tar distiller's works capable of dealwill not mar or drop the things you are handling. Right in this connection I will say that I cannot find
weezers that suit me. So I make iny own, and you can tweezers that suit me. So I make iny own, and you can
do the same if you will by selecting some nice steel. Then In selecting brushes, you will have to be very particuar and secure the open and straight bristle brushes, which are also hard to find these latter years. Take all the coarser brushes and hold them on a coarse grind-
tone, running them whole length, both ways; this akes off the new rough end of the bristles before using calipers, countersinks, files, etc., etc. Besides this, I have adopted the plan of making any tool I happen to ueed for any special purpose, so that by making these hase, I have accumulated quite a variety of odd tools mong them are a varied lot of millers, for milling an aising jewels, and deepening the countersink holes for roller, to set the jewel pin, and one for holding the hair spring collet, and a pair of tweezers for holding ewels while cleaning, etc., etc. As to lathes, I have ound that there is a necessity of about two lathes; pivot work, and I prefer these because they run much and yet if confined to but one lathe, I would use a small sized American lathe, with a good assortment of split chucks, particularly those with the smaller sized holes, or holding balance staffs, wheel arbors, etc, which come in use almost every day, for taking off the burr from the point of a balance pivot, which has comle rom a collapse of the case; driving the end stones
down on the end of pivots, even sometimes to the extend of heading them over inside of the hole jewel. These sinall size split chucks I have found extremely "sentimental" last nat I of tener use these split chucks, even for setting fine balance pivots, rather than take time to cement them; and while I do not advise the
use of a split chuck for this purpose in every case, yet o that the new pivot when set will "line" and be trie, and of a clear beat or swing. To make a very nice pivot the cementing process is preferable, and yet, for tearly a year, my old No. 1 American lathe was not luring that time I employed a very skillful workman to do my pivoting, and this man would not think of assure you that he put in more pivots out of line, and out of true, in the course of those few months, than I had done badly in my life. Speaking of "sentiment," I will say that too many young workmen use the lathe too much, and seem to depend on a fine-looking lathe
and handsome tools, and spend too much time in using and handsome tools, and spend too much time in using play. But don't construe this as nean'ng that one can 
do nice work with a jack knife and handsaw, for I most its connecting point of bearing with just the richt case and when this happens I take the point of a sharp

do nice work with a jack knife and handsaw, for I most
certainly believe in a good and substantial set of tools,
or I would not have taken so much space in speaking of them. Next, one must have a good bench, wide and
of good length : and if no other drawers, a shallow depth drawer, exactly in center of the bench, with no knob in front, but rather a lip running its whole length, underneath. So that wherever you place your hand you
can pull it out. This drawer I would have large and
roonyy (wide and long and extending back as far as the depth of the bench will allow, but shallow, not deep down in), and then partition it off by narrow slats, dia-
gonally across it, running these slats from the extreme gonally across it, running these slats from the extreme hand corner, so that as you reach your right hand in twisting or cramping your hand. About eight inches drawer (the name comes from the practice at watch factories, formerly using sheepskins for the bottoms).
which is made with a square frame (say like a pictur frame), sliding on slats or a groove, so that it can
drawn out toward the operator, and when so drawn the elbows will rest on this frame, with the wrists resting on the edge of the top of the bench, thus giving a having stretched across its bottom a skin or canvas, will catch and retain anything that drops or rolls from
the bench. This latter drawer I consider almost an in-
dispensable article to doing good and suceessful work. At the right hand of these two drawers named, run ning down to floor if need be, there can be a series of
drawers for tools and materials. Now with these equipments, and some others, not herein named, such as vise
file block, bench stake or anvil, and a large variety such tools as will accumsulate, 1 an ready to give you my ideas regarding the cleaning and repairing of job that you have any or considerable doubt but what you can do successfully, and never leave a job worse
than you found it; and never mar, cut, or slash any part of a watch. In other words, don't undertake correctly. One of my old masters told me never to while not true in every case (particularly cheap wale, screwdriver, pliers, tweezers, or any tool to deface ceed. First, be careful and not let the movement swing so as to in any way injure the balance, in taking from case, and if a lever watch, take out the balance
the first thing after getting out of case. Now see that
the mainspring is let down and then remove the screws from the plates, taking care not to damage or bend
any of the pivots as you do this. When all in pieces,
before you proceed to clean, examine with a strong glass to see if the rim of any wheel is rubbing or clashing with anything, particularly the center wheel in any cause it is not true, and if examined before cleaning the places where it drags, are a tell-tale of the nischief.
Also make any diagnosis of the watch that is needed to discover any errors from wear or accident, and corjewel, pivot, and other parts, and make all neessary
repairs before cleaning. I have been in the habit for repairs before cleaning. I have been in the habit for from all connections, and trying its freedom in all posi-
tions, and if you will try this method, you will be surprised how many you will find that bind or are not very slightest impulse by a twirl of the hand, holding
the plate. 'Then, too, a careful examination of each the plate. 'Then, too, a careful examination of each
jewel; ; you will be surprised how many are either
loose in the setting or plate. In regard to cleaning. use the old method (after trying all ways suggested)
- that of chalk (but I use the old lump chalk, for those carpenters' chalk balls are made with some kind of
paste that adheres to the plate)-and havethislump of chalk at my right hand, in a perforated bottom box so that any coarse pieces fall through to the floor, and
by rubbing the brush across it and then giving it by rubbing the brush across it and then giving it
slight rap, before applying it to plate, any hard or slight rap, before applying it to plate, any hard or
sure with the brush that is medium soft (and prepared sure grindstone as before mentioned, if a new one) brush
the plates, with an occasional breathing on the surface, clean the old oil or tarnish, and then peg out each hole dust thoroughly by striking the brush into the holes on both sides. Of course. remove all end stones, and clean out with soft pith, holding the jewels in a pair of
hook nose tweezers, mentioned. Should the plates
and wheels be very much soiled and oily, a covered dish and wheels be very much soiled and oily, a covered dish
of alcohol is indispensable, and I have had a glass stop-
per bottle, with ether, in which to dip the jewels, pal-
lets, and other small pieces. which takes the oil all off, but be sure and clean off with soft pith or pegwood
such pieces as you have thus dipped. This ether will carry all loose lint or other things to its bottom, from
hairsprings or roller table, and if held but a moment hairsprings or roller table, and if held but a moment
will do effective work, and not loosen shellac. Regarding loose jewels, 1 am not so sentimental as to refuse using some shellac, if the burnished lip has
been so thin as to be partially gone, thus loosening the jewel to hold in the jewel, by taking small and minute
particles, and placing around the edge of the jewel,
and then holding the plate or bridge over an alcohol
flame, and allowing the shellac to flow around the jewel flame, and allowing the shellac to flow around the jewel and fasten it firm, and by this process I have kept jew-
els firm in place for years, with no other attention than When you have thoroughly cleaned the different parts, the paper put the watch together, never forcing any part into place, and when serewed or pinned together, side shake to each pivot, then introduce the balance
wheel, having been once tried alone as described, and guard pin on the fork (lever) does not drag on either side, and that the jewel pin enters the slot, clearing
the opposite corner, and that the guard pin is so in position that it will not allow the pin to pass by at any \begin{tabular}{l|l|} 
point and bring the jewel pin outside the lever, or so it & and the adjustment of the hair spring, etc., etc. It is \\
will strike in hollow, or on the corners of the hollow of & often the case that there is never end shake to the bal-
\end{tabular} amount of oil (of course, oil those jewels liaving end
stones before putting watch together), your watch is
ready for the dial, and in replacing the hands you can
not be too particular about their being free and clear ng each other and the dial and being free and clear
care of the mainspring I have intentionally is the will break just aiter cleaning, but I only know that the spring (except when, after taking off the cap of
barrel, $I$ find it is all gummed up with bad oil, and then of course cleanit) I have found that a spring does
not break any oftener than is common, even if the watch is not cleaned ; but I invariably remove the bar-
el arbor and clean out the holes and the arbor itself. Of course to explain every detail of the method of
epairing the various parts of a watch would take more space than you would allow in your journal, and hence haps some of the more important items, and the most hese are broken pivots, worn pivots (sometimes requir-
the ing new ones), worn holes in plates, and at the intersec-
tion of barrel arbor, ratch and bridge of Swiss watches, etc., which, as a rule, require common sense as much as
practice, and it varies in different watches, so that the common sense rule applies the best to nearly all of
these, and if you have not got common mechanical sense, then you have mistaken your calling and should
do something else. In any of these repairs don't go it
blind, but study your case carefully and do the best blind, but study your case carefully and do the best
thing you study out. When there is a worn pivot hole
in a plate, and one side is countersunk for oil, then the countersink (and if you have not one make one, and need is where my rule, that of making a tool as the punch into the vise, and with a smooth, flat point punch (slightly cornered of course) in one hand and
colding the plate or bridge with the other, with the
countersink on the punch, have a striker tap light and countersink on the punch, have a striker tap light and
quick blows, and you move the punch around on the
side most worn (and one side is almost invariably worn ide most worn (and one side is almost invariably worn
most, throwing the wheel arbor out of upright) and
close up, even a little too much, and then with a round, mooth broach enlarge it, so that it will be right size,
and this leaves it hard and smooth.
Broken pivots, as I have hinted, I place the arbor in Broken pivots, as I have hinted, I place the arbor in
a split chuck, and if true, I drill into the staff with a drill, made from a nice piece of steel wire, the old and cutting point than it is back of the point, and I make
these as I need them, and harden simply by holding the wire in a flame till red hot, and then dash into an
apple, potato, soap, or pure rubber. Which is the best
these I have as yet been unable to determine so apple, potato, soap, or pure rubber.
of these I have as yet been unable to determine, so I
use either as the rnost handy. Take a good, tough and small pointed graver and turn a slight center in the
end of arbor I an to drill, and then by giving my lathe
a back and forward motion, I begin to drill, and by the sense of feeling I can tell whether my drill is cut th or not, and if not, I have a small, smooth oilsto cut, and if that drill will not cut, I make another.
I make my drills of very small wire, filing them point and then tap the point (holding the wire in a t, and then shape the cutting edges as spoken of plug firmly, then have a piece of steel of spring temper
filed so as to fit closely and so straight that it will not
act too wedging (and split the arbor), drive it in cut it ct too wedging (and split the arbor), drive it in, cut it
ff and turn down, finishing with an oilstone slip, and polish by running the lathe rapidly and with a piece of
hin boxwood (or hard pegwood) charged with diaman-
ine, being sure that the end of the pivot has no burr burr will cause a lack of freedom of a balance pivot
particularly. This matter of setting pivots requires a needs a long practice to do a nice job. If your split
chuck will not hold your staff or arbor true, then use cement; but in this, too, you must be sure that your
center is true, and that the sound pivot enters it peryou cannot touch it with a drill, in which case draw
the temper of the staff or arbor you are drilling, and
if it projects so little that you cannot draw the temper if it projects so little that you cannot draw the temper
without injury to the wheel, then unstake or separate without injury to the wheel, then unstake or separate
the wheel, and by drilling a hole into a piece of brass
wire, about the size of the staff you are drilling, insert wire, about the size of the staff you are drining, insert
the staff in this hole, and then heat the wire near the temper.
I consider it well for young workmen to practice pivot setting in some old and useless watch any spare ork. Unhindered, I am not over on an average of one-half hour in setting any ordinary pivot, especially
if I do not have to cement my work. If this is a baltrue and poised before putting on hair spring and roller.
There are some pivots that are underturned (to make There are some pivots that are underturned (to make possibility to put in a new one, and in this case, if an Regarding replacing broken jewels, I also keep a full Regarding replacing broken jewels, I also keep a full
stock of these, turned (the setting) to match any make or style of watch ; except, of course, Swiss watches,
and for these I keep a large assortment of sizes, both of cock and foot and wheel jewels, and a full stock once
procured, they last a long time and are a good investIn a Swiss watch, or any watch where the jewel is set into the plate, have some one of the devices for throw-
ing up the burnished lip. and then select a jewel that
just fills the space, and then with a smooth pointed just fills the space, and then with a smooth pointed
punch, such as I described I used for closing up a pivot hole, I turn this lip back by sliding this round pointed Cap jewels 1 either treat in the same manner as the wh the adjustment of the hair spring, etc., etc. It i ance to make it absolutely safe when screwed into the hrown either way, over end or on side, for such a ectly. Sometimes you meet with steel so hard that re inserted in most Swiss watches.
I have now taken up the more common repairs, and on the plate, as any unskilled workman does, for the mar nothing, and sometimes this raising of the cock by bending down the end of the cock at point where the jewel is, and thus regulate the end shake. I hardly know how to give directions how to proceed in adjusting hair springs, when they are disarranged, but if not well do in words. To commence, a hairspring, when
there is no power applied to balance from the jewel there is no power applied to balance from the jew
pin, should be, when pinned, just as free from any twist or cramping as it would be if lying flat and free at either end. and when it is pinned in the wath (at
stud and collet) it should be thus free. To bring it thu requires demonstration that cannot be made on paper,
unless you could make diagrams, too numerous for this What I have said regarding it, however, gives an idea emanded here as elsewhere. To put a watch in beat too, is a very important item, which I do by placing
harp pointed tweezers, first on one side of the arm of balance and then on the other, and so pin my hair watch should have a little oil on the face of the palle watch should have a little oil on the face of the pallet
stones. I know full well that some workmen will say that there should be none, but I can tell of scores of watches that have failed and indeed stopped simply for needs much more care than is usually given to this departinent, and as a rule even the watch factories fill
the barrel too full, that is, too long springs. Whether am correct in this or not, you cannot be too particuar in selecting the right strength, length, and width of There are many ways of replacing broken teeth in wheels, and the width of the web and the size of the asually dovetail them in, and then with the very tinipositive you have got off all soldering fluid, that it wil
port not rust the pinion into which it meshes, and be very particular to have it exactly like the rest of the teeth n same wheel, and don't mar the web of the whee
more than is possible. ng the fact that I have only made a superficial attempt o instruct younger men in the cleaning and repairing
of watches, for there is almost an endless variety of special repairs coming almost unexpectedly to any one,
even if they have been in the business a long time, as even if they have been in the business a long time, as 1
have, and as I first said, I am learning daily some new have, and as I first said, I am learning daily some new
phase of the business, and am surprised that I never space than I ought, regarding tools and bench, yet the part, that I may be enabled to do work well and quick. Besides, I have left such repairs as the chain and fusee, aprighting wheels, repairing eases, adjustment to position, heat and cold, isochronism, enlarging jewels, or
changing angles of pallet stones, ete., etc., all of which ing watches, fly backs, etc., which, too, I make a specialty of, and of chronometer escapemient watches,
which would take wore space than I feel disposed to THE NEW CENTRAL RALWAY STATION AT FRANKFORT ON THE MAIN.

THE new central railway station at Frankfort on the Main is one of the most imposing structures of modern
times, not only as regards its dimensions, but also betimes, not only as regards its dimensions, but also be-
cause of the effect which its architectural proportions
produce f buildings surrounded by gigantic perron halls can help beingimpressed with their grandeur. The beholda the Renaissance style. The interior of the perron hall of the Renaissance style. The interior of the perron hall
shown in one of our engravings is especially impressive,
and every one will admire the graceful outlines of the nd every one will admire the graceful outlines of the
heavy iron structures in the upper part, which, in consequence of their enormousheight, look from below like a spider web.
The base and the earth works were begun in the summer of 1881 , and if we take into consideration the dea of the scale on which the edifice was undertaken In 1883 , the great hall, which has a width of 220 meters and which will shortly be opened to traffic, was begun. given in one of our engravings. Inspector Eggert was erected after the plan submitted by him, and which received the prize in the competition between the dif-
ferent architects. Herr Frantz, a distinguished engineer, who undertook the general supervision of the construction, had an important part in the execution of the entrance hall for the trains, and it was he, also,
who built the perron hall, after designs of Herr Schwedler.
The middle part of the station, which contains the The middle part of the station, which contains the
porice the ticket offices, the baggage department, the police quarters and the telegraph offices, projects, a the building. and by the distinct membering of its moulding stands out conspicuously from the whole. pavilions enliven the aspect of the wings of the edifice,
the great round arched windows of which are separated from each other by powerful stone pillars. The corner
pavilions to the left in the view contain the so-called imperial apartments forthe reception of royal travelers tion rooms of the different railway administrations which is distinguished by the strength and the beaut ing and dining rooms, the ladies' rooms, the imperial 